\title{
Review on Security of Information Dissemination and Various Protocols in the Internet-of-Vehicles
}

\author{
Shradha Tembhare \\ MTech Scholar \\ Dept. of Electronics and Communication \\ OIST, Bhopal (M.P.)
}

\author{
Prof. Abhishek Mishra \\ Associate Professor \\ Dept. of Electronics and Communication \\ OIST, Bhopal (M.P.)
}

\begin{abstract}
Internet of Vehicles (IoV) is viewed as a developing worldview for associated vehicles to trade their data with different vehicles utilizing vehicle-to-vehicle (V2V) correspondences by framing a vehicular ad-hoc systems (VANETs), with roadside units utilizing vehicle-toroadside (V2R) interchanges. Performance of this smart ITS mainly owes to the design of efficient routing protocols in VANETs. Distinct features of VANETs like unsteady connectivity, high mobility and partitioning of the network have made routing of the information in VANETs difficult and challenging, hence dictating the development of efficient routing protocols. The computation of the best route measures the performance of communication whereas routing protocols takes care of communication \& routing of the data. Provision of smart communication, necessitates the analysis of routing protocols in VANET. Accordingly in this paper, reviewed various types of existing routing protocols and security approaches in VANET are discussed.
\end{abstract}

Keywords- Networking, VANET, Protocols. Routing, Security, Broadcasting. $* * * * *$

\section{INTRODUCTION}

The Internet of Things (IoT) is a novel system interfacing things, for example, clients, vehicles, and home gadgets, through electronic labels, sensors, actuators, and intuitive programming. IoT guarantees the association and correspondence between the articles by advanced methods. Situations, for example, clever vehicle framework and keen home framework can be progressively advantageous, exhaustive, and wise with the help of IoT innovation.

IoT includes cooperation between various dimensions and different fields of innovations, including equipment, picture and video preparing, information mining, remote control, information security, and protection assurance. Specialists and researchers have completed many research accomplishments on IoT related advances and their useful applications from numerous viewpoints. Note that IoT may include clients' delicate data, for example, conduct propensities, character data, and therapeutic information.

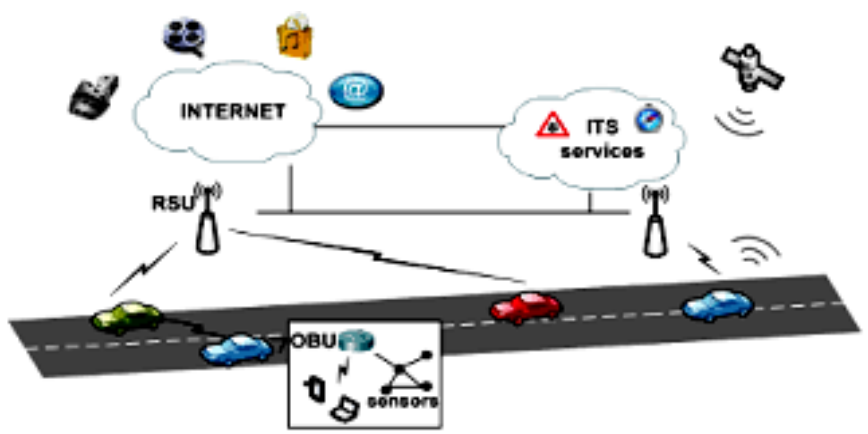

Figure 1: VANET Architecture
An ad hoc routing protocol is a convention, or standard, that controls how nodes decide which way to route packets between computing devices in a mobile ad hoc network. In ad hoc networks, nodes are not familiar with the topology of their networks. Instead, they have to discover it: typically, a new node announces its presence and listens for announcements broadcast by its neighbors. Each node learns about others nearby and how to reach them, and may announce that it too can reach them.

Mobile ad hoc networks (MANETs) are application of Mobile ad-hoc network (MANETs). MANETs were first said and presented in 2001 under "auto to-auto specially appointed portable correspondence and systems administration" applications, where systems can be framed and data can be handed-off among autos. It was demonstrated that vehicle-tovehicle and vehicle-to-roadside interchanges designs will exist together in MANETs to give street security, route, and other roadside administrations. MANETs are a key piece of the astute transportation frameworks structure. Some of the time, MANETs are eluded as Smart Transportation Networks. By 2015, the term MANET ended up being generally synonymous with the more non particular term between vehicle correspondence (IVC), notwithstanding the way that the consideration remains with respect to unconstrained frameworks organization, extensively less on the usage of structure like Street Side Units (RSUs) or cell frameworks. 


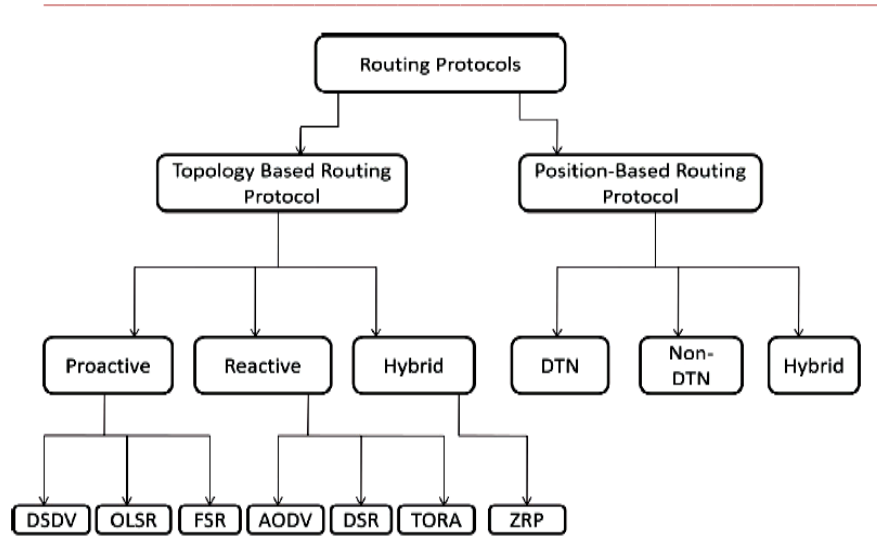

Figure 2: VANET Protocol

\section{LITERATURE SURVEY}

Danda B et.al, In this paper, we have exhibited information misrepresentation assault identification utilizing hashes for enhancing system security and upgrading the general execution by adjusting dispute window measure while sending precise data to the neighboring vehicles in an auspicious way (to enhance throughput while diminishing start to finish delay). We have likewise introduced grouping way to deal with diminish travel defer time in the event of traffic clog. Execution assessment is finished by utilizing numerical outcomes acquired from Monte Carlo reenactments.[1]

Wafa Ben et.al, Car industry is going to make a bleeding edge venture as far as vehicular advancements by giving vehicles a chance to speak with one another and make an Internet of Things made by vehicles, i.e., an Internet of Vehicles (IoV). In this unique circumstance, data scattering is extremely helpful so as to help safe basic undertakings and to guarantee unwavering quality of the vehicular framework. Be that as it may, the modern network concentrated more on safe driving and left security as an idea in retrospect, prompting the structure of unreliable vehicular and transportation frameworks. In this paper, we address potential security dangers for vehicular wellbeing applications. Specifically, we center around a delegate vehicular alarm informing framework, and we call attention to two security dangers. The main risk concerns transfer communicate message assault that powers the genuine nodes to not team up in sending the message. The second risk centers around interfering with the message handing-off to corrupt the system execution. At last, we run a careful arrangement of recreations to survey the effect of the proposed assaults to vehicular alarm informing systems.[2]

Tasneem S et.al, As an augmentation for Internet of Things (IoT), Internet of Vehicles (IoV) accomplishes brought together administration in brilliant transportation territory. With the improvement of IoV, an expanding number of vehicles are associated with the system. Substantial scale IoV gathers information from better places and different qualities, which adjust with heterogeneous nature of huge information in size, volume, and dimensionality. Huge information gathering among vehicle and application stage turns out to be increasingly more successive through different correspondence innovations, which causes advancing security assault. Be that as it may, the current conventions in IoT can't be specifically connected in enormous information accumulation in substantial scale IoV.[3]

\section{Congestion Detection}

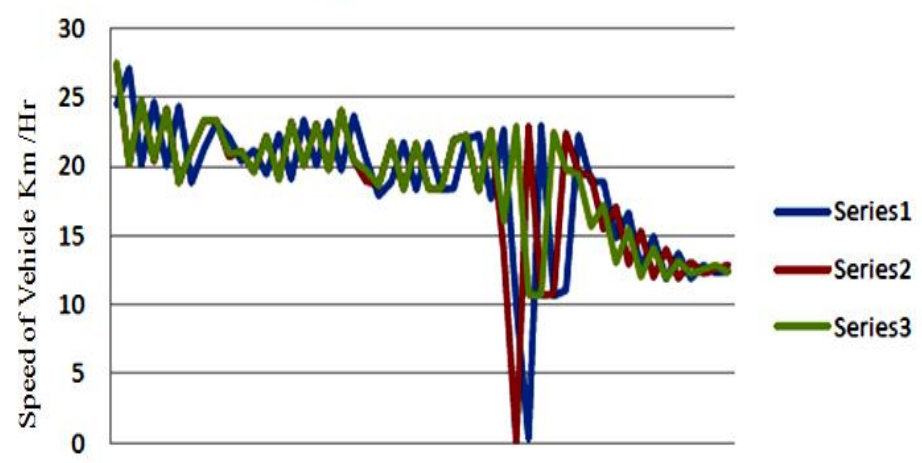

14471013161922252831343740434649

Number of Vehicles

Figure 3: congestion Detection of Vehicles

$\mathrm{X} . \mathrm{Xu}, \mathrm{H}$. Rong et.al, Weariness driving is a standout amongst the most widely recognized hazardous driving state. At the point when a driver is exhaustion, his or her response speed will be decreased, which will effectively prompt auto collisions if not controlled in time. It is a powerful method to understand the recognition and modification of the driver's exhaustion state dependent on the Internet of vehicle. Current exhaustion driving state discovery systems normally have some undeniable deformities, including low recognition precision rate, high equipment cost, awkward wearing background, high ecological prerequisite, and so forth. We propose a novel Internet-of-vehicle-situated weakness driving state identifying component dependent on information combination with the Dempster-Shafer (D-S) proof hypothesis.[4]

Wei $\mathrm{Yu}$ et.al, The Internet of Vehicle (IoV) uses systems to lead message trade and related administrations or application. Lately, shrewd urban communities and IoVs have progressed toward becoming regions of enthusiasm for the new age Internet of Things improvement, particularly since the advancement of keen transportation framework has concentrated on bettering traffic conditions. [5] 


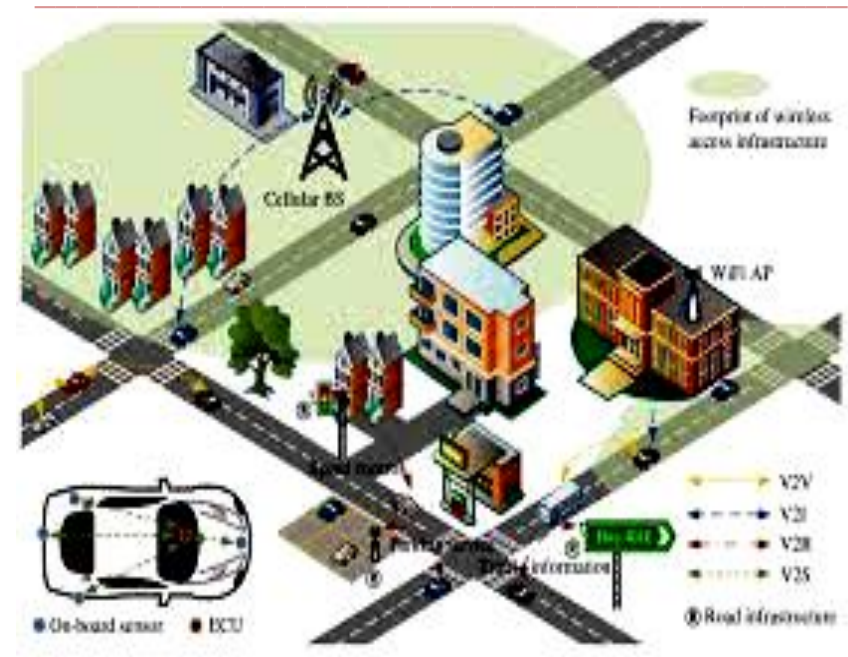

Figure 4: Communication over Vanet

An intelligent transportation framework with a system about adjacent vehicles worldwide situating framework data, for example, position and speed, and use their vehicle camcorder information for demonstrating purposes; and 3) this paper joins roadside units (RSUs) with traffic flag control and transmits vital data to the endorsement specialist (CA) for capacity. Given that RSUs are restricted in calculation capacity and storage room, we can survey and channel the data previously sending it to the CA, lessening RSUs computational weight and storage room utilization. This paper fulfills IoVs arrange security necessities of validation, non-renouncement, restrictive namelessness, and contingent recalcitrance, and, as observed from trial results, the proposed strategy is better than that of other studies.[5]

Table 1 Classifications of attacks [5]

\begin{tabular}{|l|l|l|}
\hline \multicolumn{1}{|c|}{ Attack Name } & \multicolumn{1}{|c|}{ Attack Type } & Attack Effects \\
\hline $\begin{array}{l}\text { Impersonation } \\
\text { attack }\end{array}$ & Insider attack & $\begin{array}{l}\text { Privacy and } \\
\text { confidentiality }\end{array}$ \\
\hline DoS & $\begin{array}{l}\text { Malicious, } \\
\text { active, insider, } \\
\text { network attack }\end{array}$ & Availability \\
\hline Masquerading & $\begin{array}{l}\text { Insider, active } \\
\text { attack }\end{array}$ & $\begin{array}{l}\text { Authentication } \\
\text { Authentication } \\
\text { confidentiality }\end{array}$ \\
\hline $\begin{array}{l}\text { Wormhole/tunne } \\
\text { ling }\end{array}$ & $\begin{array}{l}\text { Outsider, } \\
\text { malicious, } \\
\text { monitoring } \\
\text { attack }\end{array}$ & $\begin{array}{l}\text { Authentication } \\
\text { Insider attack } \\
\text { Bogus }\end{array}$ \\
\hline
\end{tabular}

\begin{tabular}{|c|c|c|}
\hline Black Hole & $\begin{array}{l}\text { Outsider, } \\
\text { passive attack }\end{array}$ & Availability \\
\hline Social attack & Insider attack & Integrity \\
\hline Malware & $\begin{array}{l}\text { Insider attack, } \\
\text { malicious }\end{array}$ & Availability \\
\hline $\begin{array}{l}\text { Man-in-the- } \\
\text { middle }\end{array}$ & $\begin{array}{l}\text { Insider attack, } \\
\text { monitoring } \\
\text { attack }\end{array}$ & $\begin{array}{l}\text { Confidentiality, } \\
\text { privacy and } \\
\text { integrity }\end{array}$ \\
\hline $\begin{array}{l}\text { Monitoring } \\
\text { attack }\end{array}$ & $\begin{array}{l}\text { Monitors road } \\
\text { activity }\end{array}$ & $\begin{array}{c}\text { Authenticity and } \\
\text { privacy }\end{array}$ \\
\hline Spamming & $\begin{array}{c}\text { Insider attack, } \\
\text { malicious }\end{array}$ & Availability \\
\hline Illusion Attack & $\begin{array}{c}\text { Insider, outsider } \\
\text { attack }\end{array}$ & $\begin{array}{c}\text { Authenticity and } \\
\text { data integrity }\end{array}$ \\
\hline Timing Attack & $\begin{array}{c}\text { Insider attack, } \\
\text { malicious }\end{array}$ & Integrity \\
\hline Sybil Attack & $\begin{array}{c}\text { Insider, network } \\
\text { attack }\end{array}$ & $\begin{array}{c}\text { Authentication } \\
\text { and privacy }\end{array}$ \\
\hline GPS Spoofing & Outsider attack & Authentication \\
\hline
\end{tabular}

Harinder Kaur, Meenakshi, Vehicular Ad hoc network (VANET) is an escalating field of research and laid basis for many newer technologies like Intelligent Transport Systems (ITS). Routing in VANETs plays crucial role in performance of networks. VANET protocols are classified as topology based and position based protocols. Research showed that position based protocols are more suited to VANETs as compared to topology based protocols because geographic routing does not involve an overhead and delay of maintaining routing tables instead geographic position of nodes is used for routing which can be obtained by Global Positioning System (GPS) device on vehicles. In this paper, two geographic routing protocols Anchor based Street and Traffic Aware Routing (A-STAR) and Greedy Perimeter Stateless Routing (GPSR) protocols are evaluated on real city map.[6]

W. Farooq, et.al, The Self-sufficient Ground Vehicles (AGVs) are produced to play out the protect activities autonomously to provide wellbeing to human lives, for example, in mines identification and leeway tasks. The execution of these AGVs has been upgraded in our past work by actualizing the Mobile Impromptu System (MANET) among these vehicles. In this bit of research, the Self-sufficient Airborne and Ground Vehicles (AAGVs) steering convention has been proposed, in which the aeronautical vehicles are acquainted with defeated the confinements of AGVs correspondence for scattering the 
Mines Discovery Messages (MDMs). Moreover, the bunch based plan is outlined such that the AAGVs convention can adjust continuously without influencing its execution by keeping up stable Between Mobile Correspondence (IVC) joins. The reenactment of the proposed convention in System Test system delineates that the postponement and overhead have been diminished. [7]

W. Farooq, M. A. Khan, Unmanned military vehicles (UMVs) and independent robots turned out to be a piece of present day fighting procedure to perform military battle missions and risky war field activities. The military vehicles (MVs) need to speak with each other to accomplish a few required military undertakings by and large. It has been accomplished by proposing a self-ruling military vehicles directing (AMVR) convention to build up a Mobile specially appointed system (MANET) among all military kept an eye on and unmanned vehicles to address the difficulties of current fighting. AMVR convention performs multicast correspondence among unmanned and kept an eye on military vehicles in blend to create solid coordination among them.. [8]

Z. He, D. Zhang et.al, A product characterized organize enables the making of an adaptable system design by abstracting stream control from singular gadgets to the system level. In this paper, we address the difficulties in applying SDN to grow superior Mobile systems. We display SDVN, another SDN based Mobile system engineering. It composes the topology of the Mobile systems and uses vehicle direction expectation to relieve the overhead of the SDN control and information plane correspondence. [9]

Table-II: Comparison of some Protocols

\begin{tabular}{|c|c|c|}
\hline AUTHOR & PROTOCOL & PERFORMANCE \\
\hline Hafez Seliem & $\begin{array}{c}\text { MAC \& } \\
\text { VDNET }\end{array}$ & $60 \mathrm{~S}$ \\
\hline Jos'E Grimaldo & $\begin{array}{c}\text { AODV, OLSR, } \\
\text { DSR, And } \\
\text { DSDV }\end{array}$ & $1 \mathrm{~S}$ To $300 \mathrm{~S}$ \\
\hline $\begin{array}{c}\text { Forough } \\
\text { Goudarzi }\end{array}$ & $\begin{array}{c}\text { Routing } \\
\text { Protocol }\end{array}$ & $800 \mathrm{~S}$ \\
\hline $\begin{array}{c}\text { Bhuvaneswari } \\
\text { Madasamy }\end{array}$ & MGOR & $100 \mathrm{~s}$ \\
\hline Guiyang Luo & SDNMAC & $300 \mathrm{~s}$ \\
\hline
\end{tabular}

\section{CONCLUSION}

VANET Therefore, Security and protection will likewise decide the advancement and promotion level of IoV and they are additionally the urgent reason and establishment for IoV to be put into substantial size of utilization. Vehicle clients, vehicle maker, providers, insurance agencies, open organizations and anybody successful associated in the transportation arrange all assume imperative jobs in IoV.
Vehicle producers, Correspondence specialist organizations and Middleware specialist co-ops need a progressively bound together guidelines and advancement systems to make IoV play its esteem consistently in this everything associated world. All things considered, notwithstanding the specialized elements, the imperative and supervision of governments are likewise significant.This paper gives a short prologue to IoV, depicts the qualities of IoV framework, abridge the average assaults, issues of security and current countermeasures in IoV, and furthermore the future patterns here. In this paper, we have also investigated the different routing protocols for intervehicle communication in VANET. By studying different routing protocol in VANET we have seen that further performance evaluation is required to verify performance of a routing protocol with other routing protocols based on various traffic scenarios. Now a day's ODMRP protocol is using widely in many application. Therefore in protocol based VANET architecture, can be used such protocol.

\section{REFERENCE}

[1]. Danda B. Rawat_, Moses Garuba, Lei Chen, And Qing Yang "On The Security Of Information Dissemination In The Internet-Of-Vehicles" Tsinghua Science And Technology Issnll1007-02141109/091lpp437-445 Volume 22, Number 4, August 2017

[2]. Wafa Ben Jaballah, Mauro Conti, Claudio E. Palazzi, "The position cheating attack on inter-vehicular online gaming", Consumer Communications \& Networking Conference (CCNC) 2018 15th IEEE Annual, pp. 1-6, 2018.

[3]. Tasneem S. J. Darwish, Kamalrulnizam Abu Bakar, "Fog Based Intelligent Transportation Big Data Analytics in The Internet of Vehicles Environment: Motivations Architecture Challenges and Critical Issues", Access IEEE, vol. 6, pp. 15679-15701, 2018.

[4]. X. Xu, H. Rong and S. Li, "Internet-of-vehicle-oriented fatigue driving state detection mechanism," 2016 IEEE International Conference on Ubiquitous Wireless Broadband (ICUWB), Nanjing, 2016, pp. 1-4.doi: 10.1109/ICUWB.2016.7790571

[5]. Wei Yu, Fan Liang, Xiaofei He, William Grant Hatcher, Chao Lu, Jie Lin, Xinyu Yang, "A Survey on the Edge Computing for the Internet of Things", Access IEEE, vol. 6, pp. 6900-6919, 2018.

[6]. Harinder Kaur, Meenakshi, "Analysis of VANET Geographic Routing Protocols on Real City Map" IEEE International Conference On Recent Trends in Electronics Information \& Communication Technology (RTEICT), May 19-20, 2017, India

[7]. W. Farooq, M. A. Khan, S. Rehman, N. A. Saqib and M. Abbas, "AAGV: A Bunch Based Multicast Steering Convention for Self-governing Ethereal and Ground Vehicles Correspondence in VANET," 2017 Global Gathering on Wildernesses of Data Innovation (FIT), Islamabad, 2017, pp. 315-320.

[8]. W. Farooq, M. A. Khan and S. Rehman, "AMVR: A multicast steering convention for self-sufficient military vehicles correspondence in VANET," 2017 fourteenth Worldwide 
Bhurban Meeting on Connected Sciences and Innovation (IBCAST), Islamabad, 2017, pp. 699-706.

[9]. Z. He, D. Zhang, S. Zhu, J. Cao and X. Liu, "SDN Empowered Superior Multicast in Vehicular Systems," 2016 IEEE 84th Vehicular Innovation Gathering (VTC-Fall), Montreal, QC, 2016, pp. 1-5.

[10].Rashdan, F. de Ponte Muller and S. Sand, "Execution Assessment of Activity Data Dispersal Conventions for Dynamic Course Arranging Application in VANETs," 2016 IEEE 84th Vehicular Innovation Meeting (VTC-Fall), Montreal, QC, 2016, pp. 1-5.

[11].T. Reza, T. A. Kumar and T. Sivakumar, "Position Expectation based Multicast Directing (PPMR) utilizing Kalman Channel over VANET," 2016 IEEE Worldwide Meeting on Building and Innovation (ICETECH), Coimbatore, 2016, pp. 198-206.

[12].W. Farooq, M. A. Khan and S. Rehman, "A group based multicast directing convention for Self-sufficient Unmanned Military Vehicles (AUMVs) correspondence in VANET," 2016 Universal Meeting on Figuring, Electronic and Electrical Designing (ICE 3D square), Quetta, 2016, pp. 42-48. 